${ }^{\circ}$ Entomologica Fennica. 8 January 1998

\title{
Delimitation of the pupae of the European species of the subgenus Camptochironomus (Diptera, Chironomidae)
}

\author{
Mauri Hirvenoja
}

Hirvenoja, M. 1998: Delimitation of the pupae of the European species of the subgenus Camptochironomus (Diptera, Chironomidae). - Entomol. Fennica 8: 215-218.

The pupal exuviae of the European species Chironomus (Camptochironomus) tentans (Fabricius) and C. (C.) sp. (pallidivittatus auctt.) (Diptera, Chironomidae), are redescribed. Selected characters are discussed and a tentative key for the delimination of the subgenus Camptochironomus and for the determination of these species is presented. The lectotype designation of $C$. (C.) tentans is confirmed.

Mauri Hirvenoja, Sotilaskorventie 13, FIN-01730 Vantaa, Finland

Received 13 March 1996, accepted 8 October 1997

\section{Introduction}

The key characters in the genera of the subfamily Chironominae have been recently evaluated for the pupae by Pinder and Reiss (1986). Langton $(1991,1995)$, who also has prepared a determination key for all Chironomidae at the species level for the pupae, has found several new details for the identification of the species of the genus Chironomus Meigen. In this genus the differences between the species are seemingly relatively small. However, on studying the often-neglected sternites of the exuviae with high magnitude phase contrast (or dark field) microscopy, more possibilities appear to be present for this purpose.

According to Pinder and Reiss (1986: 311), the three Holarctic subgenera Chironomus s. str., Camptochironomus Kieffer and Chaetolabis Townes are not separable as pupae. The author had no Chaetolabis material for the present study, but the characters in the subgenus Lobochironomus Ryser et al. (1985), not mentioned in the paper of Pinder and Reiss (1986), correspond to those given for Chironomus s. str. in the present paper.
Some years ago the present author had an opportunity to study the syntype of $C$. $(C$.) tentans (Fabricius 1805: 38, No. 3, sub. Tipula), two pinned female specimens, which are in the collections of the Zoological Museum of Kopenhagen, Denmark. One of the females was prepared, studied and designated as lectotype, which is confirmed here. The studied individual corresponds with present current opinion about the female of this species (Sæther 1977, Rodova 1978).

\section{Descriptions of the pupal exuviae of Camptochironomus}

\subsection{Method}

The exuviae preserved in alcohol had been cleaved dorsally with micro scissors. After this the cephalothorax was separated from the abdomen. On the object glass, in a drop of Euparal, the larger half (or both sides if material available abundantly) of the cleaved abdominal tergites were folded to the side to show the sternites without any possible disturbance of the tergal structures. Then the cephalothorax and abdomen were covered with the cover slip. 

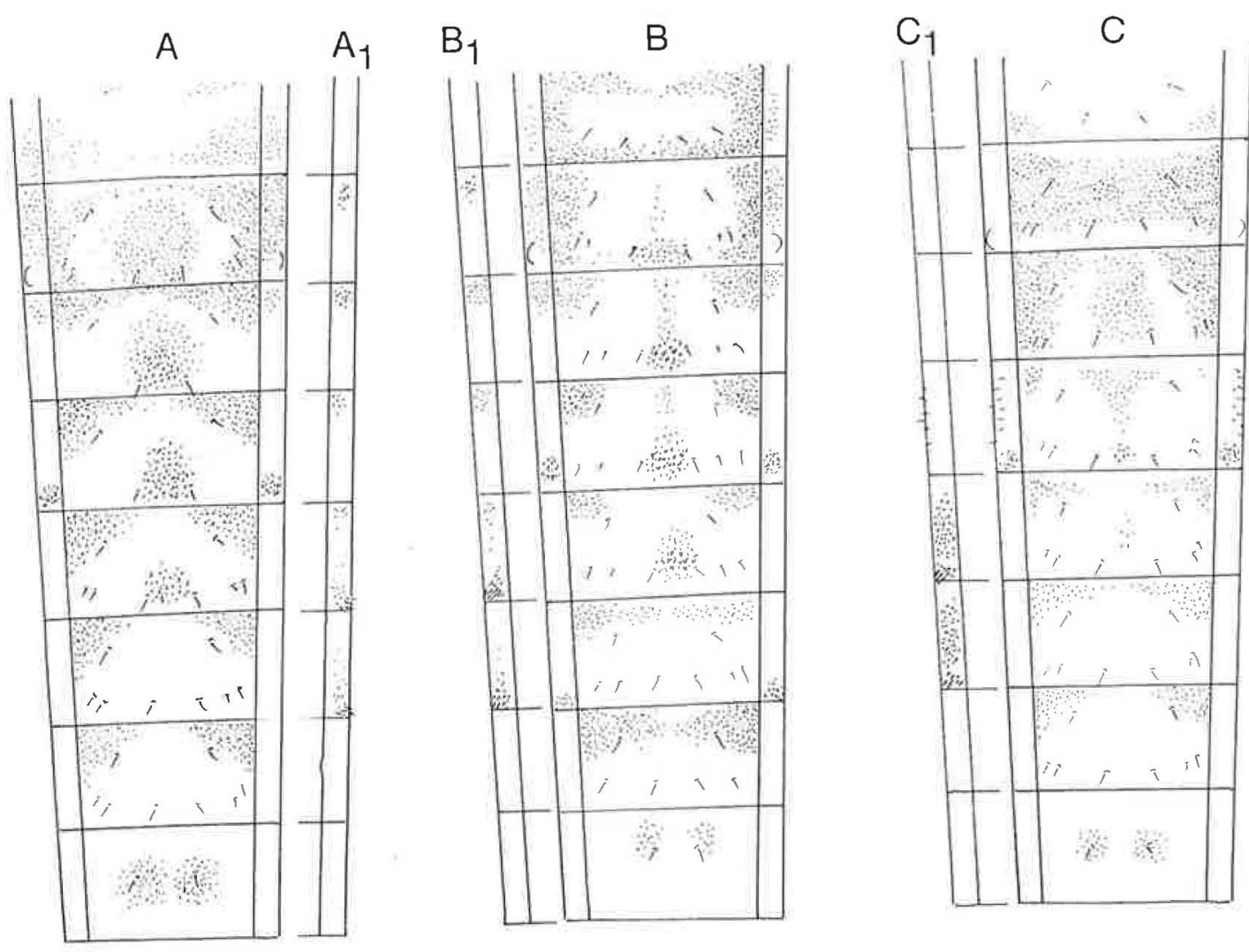

Fig. 1. Armament of the sternites and parasternites $(A-C)$ and paratergites $(A 1-C 1)$ in $(A-A 1)$ Chironomus (Camptochironomus) tentans (Fabricius), (B-B1) C. (C.) sp. (pallidivittatus auctt.) and (C-C1) Chironomus s. str. riihimakiensis Wülker.

\subsection{Chironomus (Camptochironomus) tentans (Fabricius)}

Syn. C. tentans var. pallidivittatus Malloch, ef. Hein \& Schmulbach (1971)

2 female exuviae from Riihimäki from a mud pond (M2, funnel trap), 8. and 10.6.1957, cf. Hirvenoja (1960); 1 male exuviae from Tvärminne, 6.6.1958, B. Lindeberg leg.

Exuviae 13-18 mm long; abdomen quite pale, thorax more darkened and anterodorsally strongly granulated to the base of the wing sheaths. Cephalic tubercles triangular about $150 \mu \mathrm{m}$ long and broad, each with a subapical seta and proximally quite near each other. Basal ring about $230-270 \times$ $110-140 \mu \mathrm{m}$, its tracheal patch with about $25-30$ tracheoles across, about $2 \mu \mathrm{m}$ in diameter.

Shagreen patches on tergites quite typical of the genus, extending on tergites 4-6 antero- and posterolaterally quite near the paratergites; points on the tergites enlarge posteriorly. On segment 2 quite large pedes spurii and 91-105 hooklets are present; the hooklets in the middle of their row with some minute dorsal denticles. Intersegmental spinules are present behind tergites 4 and 5. The segments are more or less crumpled, which may make it difficult to discern the smallest spinules.

There are small patches of spinules on the anterior part of paratergites 2-4(5) (Fig. 1 $\mathrm{A}_{1}$ ). On the posterior ends of paratergites 5 and 6 are the common patches of stronger spines, which spread more or less anteriorly, but paratergites 5-6(7) are not clearly spinulated. Parasternites (Fig. 1A) 1-2 widely spinulated. Small patches are also on the anterior end of parasternite 3 , precisely under the corresponding patch of paratergite 3 . Points on the pleural region on segment 4 are not ob- 
served. Spinules on sternites and parasternites have been observed as in Fig. 1A.

The number of lateral setae on segments $1-8$ : $1,3,3+1,3+1$, (and taeniated) $3-4,4,4,4$. The Spurs on segment 8 have $6-8$ fine points apically. The anal lobe fringe of taeniae (Langton \& Armitage 1995: 11) is multiserial, difficult to count, 150-191 in number.

\subsection{Chironomus (Camptochironomus) sp.}

Syn. C. (C.) pallidivittatus auctt.

1 female and 5 male exuviae from Riihimäki from a mud pond (M2, funnel trap), 9.6.1957, cf. Hirvenoja (1960).

Exuviae 12-14 mm long; abdomen brunescent, thorax more darkened and anterodorsally strongly granulated to the base of the wing sheaths. Cephalic tubercles about $150 \mu \mathrm{m}$ long and $100 \mu \mathrm{m}$ broad, each with a subapical seta and proximally not very near each other. Basal ring about 220 $270 \times 100-110 \mu \mathrm{m}$, its tracheal patch is very dense.

Shagreen on tergites typical of the genus, extending on tergite (4-)5(-6) antero- and posterolaterally quite near the paratergites, on the others not much over the seta $D_{i}$; points on the posterior part of the tergite clearly larger than those standing anteriorly. On segment 2 quite large pedes spurii and 76-92 hooklets; the hooklets in the middle of the row with some minute dorsal denticles. Intersegmental spinules are behind tergites 4 and 5 , but a few very rudimentary ones may be found also behind the 6 th. The segments are somewhat crumpled, which may make it difficult to discern the smallest spinules.

There are small patches of spinules on the anterior part of paratergites 2-4(5) (Fig. 1B B $_{1}$; on the posterior ends of paratergites 5 and 6 are the common patches of stronger spines, which spread more or less anteriorly, but paratergites 5-6 are not clearly spinulated. Parasternites (Fig. 1B) 1-2 are clearly spinulated. Small patches of spinules are also on the anterior end of parasternite 3 precisely under the corresponding patch of paratergite 3 , as well as on the posterior end of the parasternite 6 precisely under the patch of the paratergite. Points on the pleural region on segment 4 are not observed. Spinules on sternites have been observed as illustrated in Fig. 1B; the spines between the setae $V_{5}$ on sternites 3-5 are unusually approximately as strong as the smallest tergal points.

The number of lateral setae on segments 1-8: $0,3,3+1,3+1$, (and taeniated) $3,3,4,4-5$. The Spurs on segment 8 have $5-11$ fine points apically. The anal lobe fringe of taeniae is multiserial, difficult to count, at least 128-152 in number.

\section{Discussion}

Langton $(1991,1995)$ uses as the key character distinguishing $C$. (C.) tentans from $C$. (C.) sp. (sub. C. (C.) pallidivittatus) the anterior shagreen band of sternite 3, which on the latter species is much more broken medially. There are, however, also important differences especially in the median armament of the sternites (Fig.1A and B), the observation of which requires some more care in the preparation of the exuviae.

The intraspecific variation of the spinulation is still not very well known. The illustration is approximate as the small size and great number of the spinules make it nearly impossible to draw an accurate small figure. Therefore, the armament has been given in the present paper very schematically, which only roughly shows the spinulated parts.

There is one feature common in the exuviae of both species, which is unknown from the other species of the genus Chironomus. This character is the presence of the obviously plesiomorphous small patches of spinules on the anterior end of paratergites $2-4$. These groups of spinules may be hard to detect if the exuviae are not cut open. It is important to differentiate these patches of spinules from those of the parasternites, which are quite easy to find and more-or-less common in the entire genus Chironomus.

As a theoretical plesiomorphous phase a structure of the exuviae can probably be considered, where all parts of the abdominal segments are more or less roughly spinulated. The development of the spinulation advances probably then by reductions and/or constructions. In the genus Chironomus the structure of the tergites stays relatively stable, but that of the sternites shows varieties of different grades mostly by various degenerations.

The pleural points of abdominal segment 4 (Fig. 1C) may for a group of species be interpreted 
as an apomorphous product of a constructive, unknown phase during evolution. They seem to be then plesiomorphously (stasigenese!) present in many species, but disappear again obviously gradually, which is then again a relatively apomorphous phase. It may, however, be that the lack of these points in Camptochironomus belongs to a plesiomorphous phase in the history of the genus Chironomus.

The degree of the reduction of the sternal spinules in Camptochironomus is in comparison to the species of Chironomus different and may be considered more apomorphous in some sternites. As an example, in Fig. $1 \mathrm{C}-\mathrm{C}_{1}$ the corresponding parts of the exuviae of Chironomus s. str. riihimakiensis Wülker are illustrated. Relatively, apomorphous features in the subgenus Camptochironomus which are also found in species of the genus Chironomus are obviously the following characters:

- the reduction of the patches of spinules on the posterior comer of segment 7 (strong patches are present in the species near Chironomus s. str. plumosus Linnaeus sensu auctt.)

- the not or only quite sparsely spinulated paratergites of segments 5 and 6(7) (present often in Chironomus)

- the total or nearly total lack of the intersegmental spinules behind tergite 6 (present on some species in Chironomus)

- for instance, in comparison with C. s. str. riihimakiensis (Fig. 1C), the spinulation of sternite 2 is more apomorphous in both species of Camptochironomus.

\section{Summary}

The following results should be tested:

1(2) Small patches of spinules anteriorly on the paratergites 2-4 present. Intersegmental membranes behind tergites 4-5 clearly spinulated. Patches of spines present on the hind corners of segments 5-6 only, but paratergites of these segments not clearly spinulated on its whole length. Pleurae of segment 4 smooth
Camptochironomus ... 3

2(1) Small patches of spinules anteriorly on paratergites 2 4 absent

Chironomus s. str. (Lobochironomus, ?Camptolabis)

3(4) Anterior shagreen band of sternite 3 continuous or broken, if not continuous, spinules on the anterior corners of this sternite spread medially clearly over setae $V_{i}$; median patches of spinules decrease in size from sternite 2 to 4 C. (C.) tentans

4(3) Patches of spinules on the anterior corners of sternite 3 reach medially approximately to the $V_{1}$ setae; median patches of spinules increase in size from sternite 2 to 4; the spinules between the $V_{5}$ setae are unusually strong C. (C.) sp. (pallidivittatus auctt.)

Acknowledgement. Sincere thanks are due to $\mathrm{Mr}$. Donald Smart for the English language revision.

\section{References}

Fabricius, J. C. 1905: Systema antliatorum secundum ordines, genera, species. - Brunsvigae. 373 pp. +30 pp.

Hein, J. \& Schmulbach, J. C. 1971: Intraspecific and interspecific breeding behavior of Chironomus pallidivittatus (Dipt., Chironomidae). — Can. Ent. 103: 458-464.

Hirvenoja, M. 1960: Ökologische Studien über die Wasserinsekten in Riihimäki (Südfinnland). I. Chaoborinae (Dipt., Culicidae). - Ann. Entomol. Fenn. 26: 31-44.

Langton, P. H. 1991: A key to pupal exuviae of West Palearctic Chironomidae. - Mimeogr. 386 pp.

Langton, P. H. 1995: A key to pupal exuviae of West Palearctic Chironomidae. Update of the genus Chironomus. - Mimeography. 14 pp.

Langton, P. H. \& Armitage, P. D. 1995: Rheotanytarsus rioensis (Diptera: Chironomidae) a new species of the pentapoda group from the Canary Islands. - Br. J. Entomol. Nat. Hist. 8: 11-17.

Pinder, L. C. V. \& Reiss, F. 1986: 10. The pupae of Chironominae (Diptera: Chironomidae) of the Holarctic region. - Keys and diagnoses. - Ent. Scand. Suppl. 28:299-456.

Rodova, R. A. 1978: Opredelitel' samok komarov zvontsov triby Chironomini. [Key to the females of midges of the tribe Chironomini.] — Izd. Nauka, Leningrad. 141 pp. [In Russian.]

Ryser, H. M., Wülker, W. \& Scholl 1985: Revision der Gattung Chironomus Meigen (Diptera). X. Lobochironomus n. subg. (C. montuosus n. sp., C. storai Goetgh., C. mendax Storå). - Revue Suisse Zool. 92(2): 385-404.

Sæther, O. A. 1977: Female genitalia in Chironomidae and other Nematocera, morphology phylogenies, keys. Bull. Fish. Res. Board of Canada 197: 1-209. 